\title{
Formation of buried TiN in glass by ion implantation to reduce solar load
}

\author{
Gary S. Was ${ }^{\text {a) }}$ and Victor Rotberg \\ Department of Nuclear Engineering and Radiological Sciences, University of Michigan, Ann Arbor, \\ Michigan 48109 \\ Dennis Platts, John Bomback, and Robert Benoit \\ Glass Division, Ford Motor Company, Dearborn, Michigan 48121
}

(Received 5 September 1995; accepted for publication 1 June 1996)

\begin{abstract}
$\mathrm{Ti}$ and $\mathrm{N}$ were implanted into soda lime glass to doses up to $4.5 \times 10^{17} \mathrm{~cm}^{-2}$ to reduce solar load and infrared transmission. Analysis of the Ti+N implant distributions by Rutherford backscattering spectrometry and x-ray photoelectron spectroscopy (XPS) revealed profiles which closely followed each other as designed by the selection of implant energies. XPS, x-ray diffraction, and selected area electron diffraction in transmission electron microscopy also confirmed the existence of a crystalline B1-type, cubic TiN layer, $140 \mathrm{~nm}$ wide, at doses greater than $9 \times 10^{16} \mathrm{~cm}^{-2}$. Optical measurements showed that the fraction of infrared radiation reflected was increased by almost a factor of 4 compared to an increase of 1.8 in the visible region. The percentage of the total solar energy rejected reached $80 \%$ at the highest dose, indicating that the buried TiN layer is highly effective in reducing solar energy transmission. (c) 1996 American Institute of Physics. [S0021-8979(96)07117-4]
\end{abstract}

\section{INTRODUCTION}

Implantation of selected ions into glass is known to affect optical properties in selected wavelength regimes. Reducing transmission of UV or IR radiation is of great practical importance in, for instance, solar load control in buildings and automotive vehicles. Achieving these properties through implantation, as opposed to surface coating, has the advantages that the interface is less distinct yielding potentially greater surface durability and the technique uses less material. One such application is the formation of a buried TiN layer by sequential implantation of Ti and $\mathrm{N}$. The formation of TiN by ion implantation was first demonstrated by Rai et al. ${ }^{1}$ who implanted $104 \mathrm{keV} \mathrm{Ti}^{+}$at $5 \times 10^{17} \mathrm{~cm}^{-2}$ and $35 \mathrm{keV} \mathrm{N}^{+}$at $5 \times 10^{17} \mathrm{~cm}^{-2}$. Mazzoldi et al. ${ }^{2}\left(190 \mathrm{keV} \mathrm{Ti}{ }^{+}\right.$ and 40,70 , or $\left.100 \mathrm{keV} \mathrm{N}^{+}\right)$, Battagten ${ }^{3}\left(190 \mathrm{keV} \mathrm{Ti}^{+}\right.$at $5 \times 10^{16} \mathrm{~cm}^{-2}$ and $70 \mathrm{keV} \mathrm{N} \mathrm{N}^{+}$at $2 \times 10^{17} \mathrm{~cm}^{-2}$ ), and Bertoncello ${ }^{4}\left(30-190 \mathrm{keV} \mathrm{Ti}^{+}\right.$at $5 \times 10^{16} \mathrm{~cm}^{-2}$ and $15-100$ $\mathrm{keV} \mathrm{N}+5-20 \times 10^{16} \mathrm{~cm}^{-2}$ ) reported the formation of a titanium oxynitride $\left(\mathrm{TiO}_{x} \mathrm{~N}_{y}\right)$ following implantation into amorphous $\mathrm{SiO}_{2}$. Ion implantation in silica glass usually results in an increase of the refractive index, $n$, due to a compaction effect. ${ }^{5,6}$ Implantation of nitrogen produces a large change in $n$ which has been attributed to the formation of silicon oxynitride. ${ }^{7-11}$ While coatings are the common method of changing the reflection or absorption of glass, little work has been done concerning the formation of specific buried compounds and their effects on optical properties. In this article, we report on the formation of a crystalline TiN phase by sequential implantation of $\mathrm{Ti}$ and $\mathrm{N}$ above a threshold dose. Also reported are the resulting properties of transmittance as a function of wavelength for $\mathrm{Ti}+\mathrm{N}$ implanted soda lime glass.

\footnotetext{
${ }^{a)}$ Corresponding author: 1911 Cooley Bldg., Department of Nuclear Engineering and Radiological Sciences, University of Michigan Ann Arbor, MI 48109; Electronic mail: gsw@umich.edu
}

\section{EXPERIMENT}

Implantations were made into 0.18 -cm-thick clear float soda lime glass, produced commercially by the Glass Division of Ford Motor Company, of composition (weight percent) $73.3 \quad \mathrm{SiO}_{2}-13.6 \quad \mathrm{Na}_{2} \mathrm{O}-8.6 \quad \mathrm{CaO}-4.0 \quad \mathrm{MgO}-0.2$ $\mathrm{Fe}_{2} \mathrm{O}_{3}-0.2 \quad \mathrm{SiO}_{3}-0.1 \quad \mathrm{Al}_{2} \mathrm{O}_{3}$. The process consisted of $\mathrm{Ti}$ implantation followed by $\mathrm{N}$ implantation to the same dose, and at energies selected so that the resulting depth distributions of the two species overlapped. The transport of radiation in matter (TRIM) code $^{12}$ was used to determine the energies of $\mathrm{Ti}^{+}$and $\mathrm{N}^{+}$to produce overlapping concentration profiles. Mean ranges and straggling $[R p,(\Delta R p)]$ in silica are: ${ }^{12} \mathrm{Ti}(87 \mathrm{keV})=75 \mathrm{~nm}(25 \mathrm{~nm})$, and $\mathrm{N}(30 \mathrm{keV})=74 \mathrm{~nm}$ $(26 \mathrm{~nm}) . \mathrm{Ti}^{+}$was implanted first at $87 \mathrm{keV}$ to eight doses from $2 \times 10^{16} \mathrm{~cm}^{-2}$ to $45 \times 10^{16} \mathrm{~cm}^{-2}$, followed by $\mathrm{N}^{+}$implantation at $30 \mathrm{keV}$ to the same doses. Since the ion beam was primarily $\mathrm{N}_{2}^{+}$, the accelerating voltage was $60 \mathrm{kV}$. Implantations were made at a current density below $1 \mu \mathrm{A} / \mathrm{cm}^{2}$ in a vacuum better than $1 \times 10^{-6}$ Torr. Implantations were nominally performed at room temperature, however beam heating caused the surface temperature to rise by $<200{ }^{\circ} \mathrm{C}$. No postimplantation annealing was performed.

Analysis of the implants was performed by Rutherford backscattering spectrometry (RBS) using $2 \mathrm{MeV} \mathrm{He}^{++}$at a scattering angle of $170^{\circ}$. Composition profiles were determined with the aid of two computer codes, RUMP ${ }^{13}$ and PROFILE. ${ }^{14}$ X-ray photoelectron spectroscopy (XPS) coupled with $3 \mathrm{keV} \mathrm{Ar}{ }^{+}$sputter depth profiling was also conducted to determine composition profiles and chemical bonding states of the constituents. Analysis was done on a Perkin-Elmer PHI 5400 XPS system with monochromatic Mg K $\alpha$ (1253.6 $\mathrm{eV}) \mathrm{x}$ rays in a vacuum chamber at a base pressure of $4 \times 10^{-9}$ Torr maintained at $7 \times 10^{-8}$ Torr during argon sputtering. Sputtering was done in 1 or $2 \mathrm{~min}$ intervals for a total of $35 \mathrm{~min}$. Detailed energy spectra were recorded in multiplex mode for the $\mathrm{C}_{1 s}, \mathrm{O}_{1 s}, \mathrm{Ti}_{2 p}, \mathrm{Si}_{2 p}, \mathrm{~N}_{1 s}$, and $\mathrm{Ar}_{1 s}$ lines (17.9 eV pass energy, $0.1 \mathrm{eV} / \mathrm{step} ; 0.1 \mathrm{~s} / \mathrm{step}$ and multiple 
sweeps for each element). Charge neutralization was used with an electron energy of $0.9 \mathrm{eV}$.

Phase analysis of the implanted layer was determined using glancing angle $\mathrm{x}$-ray diffraction. $\mathrm{A} \mathrm{Cu} \mathrm{K} \alpha 1$ x-ray source was used with a Seemann-Bohlin x-ray diffractometer in which the angle between the sample surface and the $\mathrm{x}$-ray beam was set at $2^{\circ}$ and the detector angle ranged from $8^{\circ}$ to $70^{\circ}$. The existence and spatial extent of the buried crystalline phase was confirmed using selected area electron diffraction on cross-section transmission electron microscopy (TEM) samples. Samples were made by gluing together two pieces of ion implanted glass and cutting the sandwich into a disk of $1 \mathrm{~mm}$ thickness. The disk is then ground down to $100 \mu \mathrm{m}$ thickness using lapping paper and then dimpled down to $1-2 \mu \mathrm{m}$ thickness using a final stage polish of 0.05 $\mu \mathrm{m} \mathrm{Al}_{2} \mathrm{O}_{3}$ slurry. The sample was then epoxied onto a slotted copper grid and ion milled with $1 \mathrm{~mA}^{\circ} \mathrm{Ar}^{+}$at $5 \mathrm{kV}$ and an angle of $8^{\circ}$. A conductive coating of carbon was evaporated onto the sample prior to examination in TEM. Bright field and dark field images were obtained at $100 \mathrm{kV}$ using a JEOL $100 C X$ and selected area diffraction (SAD) was conducted at a camera length of $120 \mathrm{~cm}$.

Transmission and reflectance at near-normal incidence were measured with a Perkin-Elmer LAMBDA9 UV/VIS/ NIR spectrophotometer operated with a dual "VW" absolute specular reflectance attachment. Specific operation of the attachment is explained more fully in Ref. 15. Solar values were determined by weighting measured values with the relative intensities of the solar spectrum using air mass 2 for solar distribution from ISO 9050 and the air mass 2 data of Moon. ${ }^{16}$ The wavelength ranges of interest are $280-2120 \mathrm{~nm}$ for "total solar" values, $280-400 \mathrm{~nm}$ for UV, 400-720 nm for visible (VIS), and 720-2120 nm for near infrared (NIR).

Transmission and reflection of models of the implanted glass were calculated using MULTFILM described in Ref. 17. This code applies the Fresnel equations to layered structures using optical properties of multi-component layers derived from effective medium theory as developed by Bruggeman and described by Martina. ${ }^{18}$

\section{RESULTS AND DISCUSSION}

RBS spectra of the region containing the Ti peak for eight samples implanted with $\mathrm{Ti}(87 \mathrm{keV})$ and $\mathrm{N}(30 \mathrm{keV})$ to the same dose are shown in Fig. 1. RBS indicates that the amount of retained $\mathrm{Ti}$ was 1.4, 3.2, 6.3, 7.4, 9.0, 23.0, 30.0, and $45.0 \times 10^{16} \mathrm{~cm}^{-2}$. There was some loss $(<10 \%$ of the amount initially implanted) of $\mathrm{Ti}$ following subsequent $\mathrm{N}$ implantation (probably due to sputtering). The heights of the peaks rise monotonically through a retained dose of $2.3 \times 10^{17} \mathrm{~cm}^{-2}$ while both the peak shape and centroid remain relatively constant. At a retained dose of $3 \times 10^{17} \mathrm{~cm}^{-2}$, the Ti peak broadens considerably, indicating the presence of $\mathrm{Ti}$ at greater depths. A fit to the RBS profile using RUMP resulted in both a Ti and $\mathrm{N}$ content of $\sim 33$ at. \%, extending over a depth of $180 \mathrm{~nm}$. The migration of Ti to still greater depths is also seen in the highest dose $\left(4.5 \times 10^{17} \mathrm{~cm}^{-2}\right)$ sample, where the amount of $\mathrm{Ti}$ (and $\mathrm{N}$ ) is $\sim 37$ at. \% and extends to a depth of $220 \mathrm{~nm}$. The deep penetration of Ti may be due to the formation of a crystalline phase as dis-

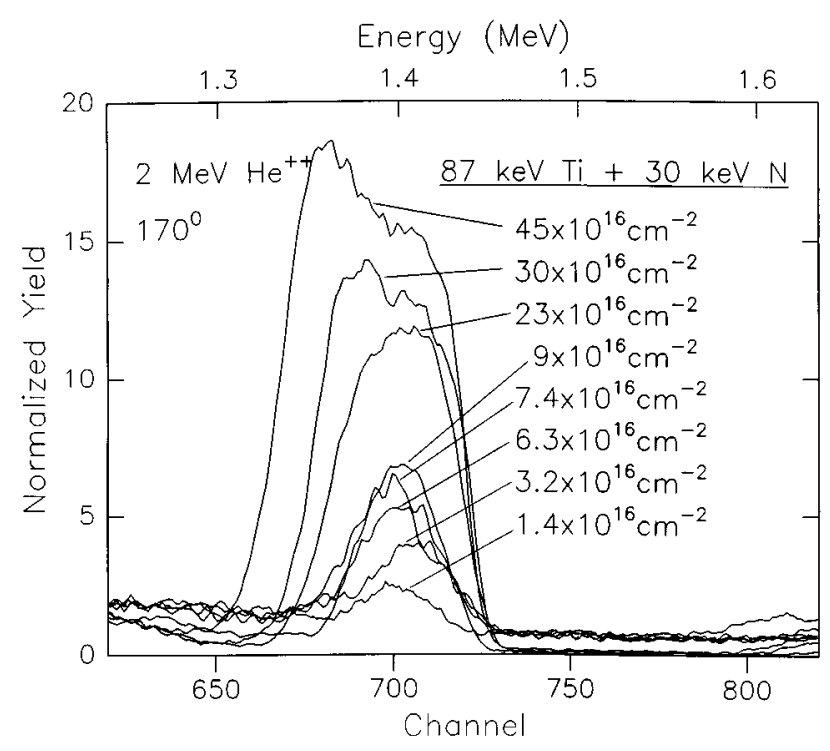

FIG. 1. Rutherford backscattering spectra of $\mathrm{Ti}+\mathrm{N}$ implantations into soda lime glass showing retained amounts of $\mathrm{Ti}$ after $\mathrm{N}$ implantation.

cussed later. The flattened composition profile of the high dose implants is confirmed by sputter depth profiling followed by XPS, Fig. 2. There is a broad region of nearly constant composition for both the $\mathrm{Ti}$ and $\mathrm{N}$ profiles and the $\mathrm{N}$ profile closely follows that of Ti. These results are in close agreement with those of Mazzoldi et al. ${ }^{2}$ who showed that at an energy ratio of $2.7,190 \mathrm{keV}(\mathrm{Ti})-70 \mathrm{keV}(\mathrm{N})$ [vs. 2.9 for our experiments], the implanted $\mathrm{N}$ profile closely follows the Ti profile.

XPS also yields information on the binding energy of the species, which can be used to determine its chemical state in the solid. Figure 3 shows four spectra of the $\mathrm{Ti}_{2 p}$ and $\mathrm{Si}_{2 p}$ peaks at depths corresponding to the four arrows in Fig. 2. On the surface, two $\mathrm{Ti}_{2 p}$ peaks are evident at about 458 and $463.8 \mathrm{eV}$, and a $\mathrm{Si}_{2 p}$ peak at $102.4 \mathrm{eV}$. After sputtering for 11 min, another $\mathrm{Ti}_{2 p}$ peak has emerged at $\sim 454.7 \mathrm{eV}$ and the peak at $458 \mathrm{eV}$ is diminished considerably. At this depth, the Ti $(\mathrm{N})$ concentration is about 36 at. \% (33 at. \%). There is

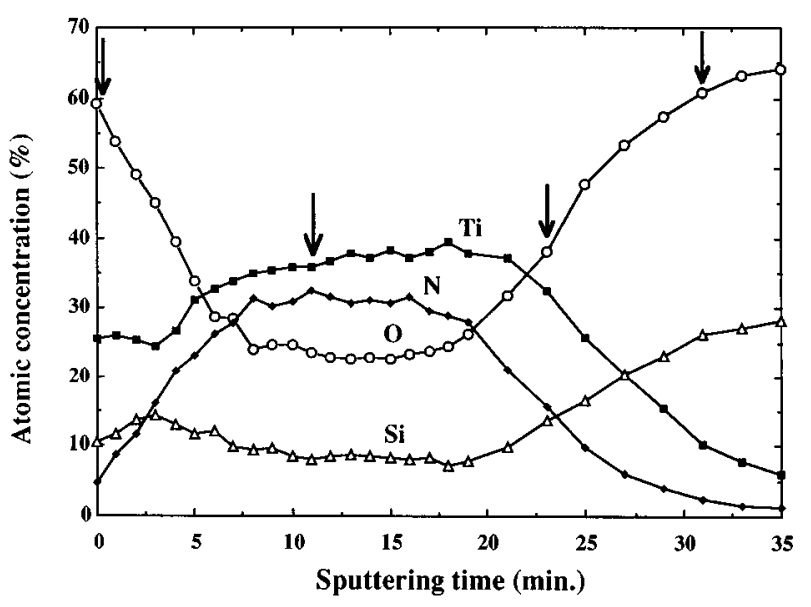

FIG. 2. Ti and $\mathrm{N}$ concentration profiles during sputter depth profiling as measured using XPS, for Ti and $\mathrm{N}$ doses of $3.0 \times 10^{17} / \mathrm{cm}^{-2}$. 


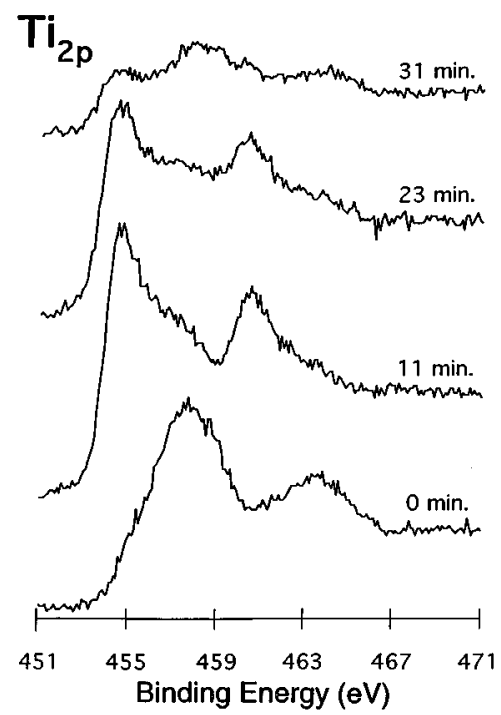

(a)

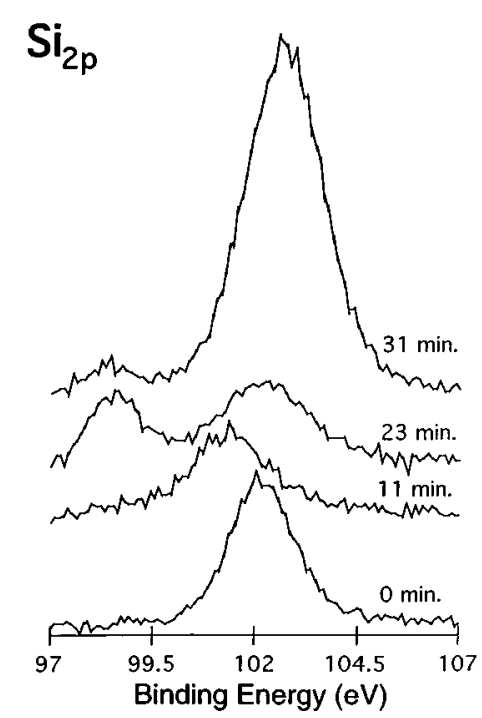

(b)

FIG. 3. Binding energy spectra for (a) Ti and (b) Si, in soda lime glass implanted to $3 \times 10^{17} \mathrm{~cm}^{-2} \mathrm{Ti}+\mathrm{N}$ and after $0,11,23$, and $31 \mathrm{~min}$ of sputtering by a $3 \mathrm{keV} \mathrm{Ar}^{+}$ion beam.

little change in the $\mathrm{Ti}_{2 p}$ peaks after sputtering for $23 \mathrm{~min}$, but an additional $\mathrm{Si}_{2 p}$ peak has emerged at $98.5 \mathrm{eV}$. Sputtering for $31 \mathrm{~min}$ results in a drop in the $454.7 \mathrm{eV}$ peak, a rise in the peak at $458 \mathrm{eV}$ of $\mathrm{Ti}_{2 p}$ and a sharp increase in the $102.4 \mathrm{eV}$ $\mathrm{Si}_{2 p}$ peak. Ti (N) concentration here is 10 at. \% (3 at. \%).

Bertoncello et al. ${ }^{2,4}$ have interpreted the $\mathrm{Ti}_{2 p}$ peaks at $\sim 454$ and $\sim 458.5 \mathrm{eV}$ to be due to titanium silicide and titanium oxide, respectively, in glass implanted with Ti. (The $463.8 \mathrm{eV}$ peak is also from $\mathrm{TiO}_{2}$.) They suggest that subsequent $\mathrm{N}$ implantation broadens the previously distinct $\mathrm{Ti}_{2 p}$ doublet due to the formation of metallic precipitates $(\sim 453$ $\mathrm{eV})$ and titanium oxynitride $(458 \mathrm{eV})$. They also suggest that the lower energy $\mathrm{Si}_{2 p}$ peak is due to the formation of a new compound involving implanted $\mathrm{N}\left(\mathrm{SiO}_{x} \mathrm{~N}_{y}\right)$. In our results, the peak at $458 \mathrm{eV}$ is largest at moderate $\mathrm{Ti}$ and low $\mathrm{N}$ concentrations (shallow and deep), and is consistent with an oxide phase. At intermediate depths where the $\mathrm{Ti}$ and $\mathrm{N}$ concentrations are high, the $454 \mathrm{eV}$ peak is prevalent, and it is likely due to titanium nitride. Bertoncello et al. ${ }^{2,4}$ have also reported that peaks corresponding to TiSi are absent following a $\mathrm{Ti}+\mathrm{N}$ implantation. XPS measurements by $\mathrm{Wu}^{19}$ on TiN films confirm a $\mathrm{TiO}_{2}$ peak at an energy near $459 \mathrm{eV}$ and a TiN peak at $454.8 \mathrm{eV}$, consistent with our interpretation. The behavior of the $\mathrm{Si}_{2 p}$ peaks is also consistent with nitride formation. The high-energy peak, likely due to $\mathrm{SiO}_{2}$, is largest at the surface and deep into the sample. In the implanted region where $\mathrm{TiN}$ is formed, the $\mathrm{SiO}_{2}$ peak diminishes in intensity and an additional low-energy peak emerges which may be due to formation of a silicon oxynitride phase, as postulated by Bertoncello. Our results suggest that small amounts of $\mathrm{Ti}$ in glass are most likely present as $\mathrm{TiO}_{2}$, and that significant quantities of $\mathrm{N}$ are required before a TiN phase forms. The onset and disappearance of the TiN phase is also coincident with the drop and rise, respectively, in the oxygen concentration, as expected.
Confirmation of the presence of a TiN phase is provided by $\mathrm{x}$-ray diffraction shown in Fig. 4 . The curves are for a $3 \times 10^{17} \mathrm{~cm}^{-2} \mathrm{Ti}+\mathrm{N}$ implantation, a $9 \times 10^{16} \mathrm{~cm}^{-2} \mathrm{Ti}+\mathrm{N} \mathrm{im}-$ plantation, and a $2 \times 10^{17} \mathrm{~cm}^{-2}$ Ti-only implantation and are plotted as intensity in counts $/ \mathrm{s} /{ }^{\circ}$ vs $2 \theta$. Note the peaks in the high dose $\mathrm{Ti}+\mathrm{N}$ implantation, which have been indexed as the (111), (200), and (220) reflections of B1-type cubic TiN phase. The lattice constant is in excellent agreement with that of the bulk material, $0.424 \mathrm{~nm}^{20}$ The inset shows a plot of the net number of counts (total minus counts from glass substrate) and reveals the (311) reflection as well.

Additional confirmation of the existence of a TiN phase is provided by bright field/dark field images of the implanted region and selected area electron diffraction of $\mathrm{Ti}+\mathrm{N}$ im-

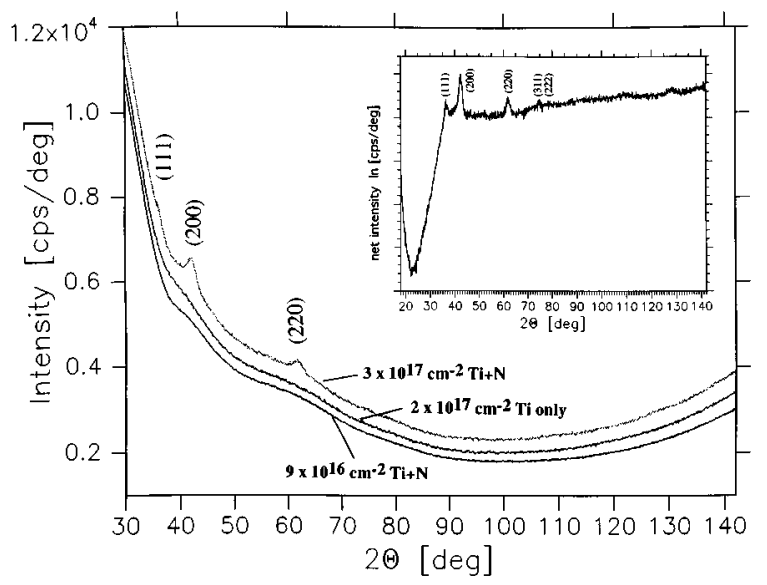

FIG. 4. Glancing angle $\mathrm{x}$-ray diffraction of soda lime glass implanted with $\mathrm{Ti}+\mathrm{N}$ to $9 \times 10^{16} \mathrm{~cm}^{-2}$ and $3 \times 10^{17} \mathrm{~cm}^{-2}$, and with Ti to $2 \times 10^{17} \mathrm{~cm}^{-2}$. The inset shows the net intensity (total counts minus counts from glass substrate) for the $3 \times 10^{17} \mathrm{~cm}^{-2} \mathrm{Ti}+\mathrm{N}$ sample and reveals two additional reflections. 
planted to $3 \times 10^{17} \mathrm{~cm}^{-2}$, Fig. 5. The bright field image shows that the TiN phase is confined to a layer approximately $140 \mathrm{~nm}$ in width and forms a sharp interface with the underlying amorphous glass phase. This is in good agreement with the approximate width of the region of equal $\mathrm{Ti}$ and $\mathrm{N}$ composition $(\sim 180 \mathrm{~nm})$ as measured by RBS, and is precisely the regime in which the TiN phase is likely to form. The dark field image is taken using the (200) reflection. Note that the (111), (200), (220), (222), and (400) reflections are clearly evident from the selected area diffraction pattern and again match the $0.424 \mathrm{~nm}$ lattice parameter. The dark field image also reveals that the grain size of the TiN crystallites is in the range $3-10 \mathrm{~nm}$.
Figure 6 shows the percent of radiation reflected for unimplanted and $\mathrm{Ti}+\mathrm{N}$ implanted clear glass for three wavelength regimes defined previously. The total solar reflection and percent of solar radiation rejected are also shown. The latter (calculated using the code, MULTFILM. ${ }^{17}$ is a combination of the amount of energy reflected and the amount of energy absorbed which is subsequently lost to the outside through conduction and convection. (The program uses transmittance data measured with a dual beam spectrometer using air in the reference beam.) The percent solar radiation rejected is of great practical importance in both automotive and architectural glazing applications. In all cases, the radiation is incident on the treated side of the glass. Note the
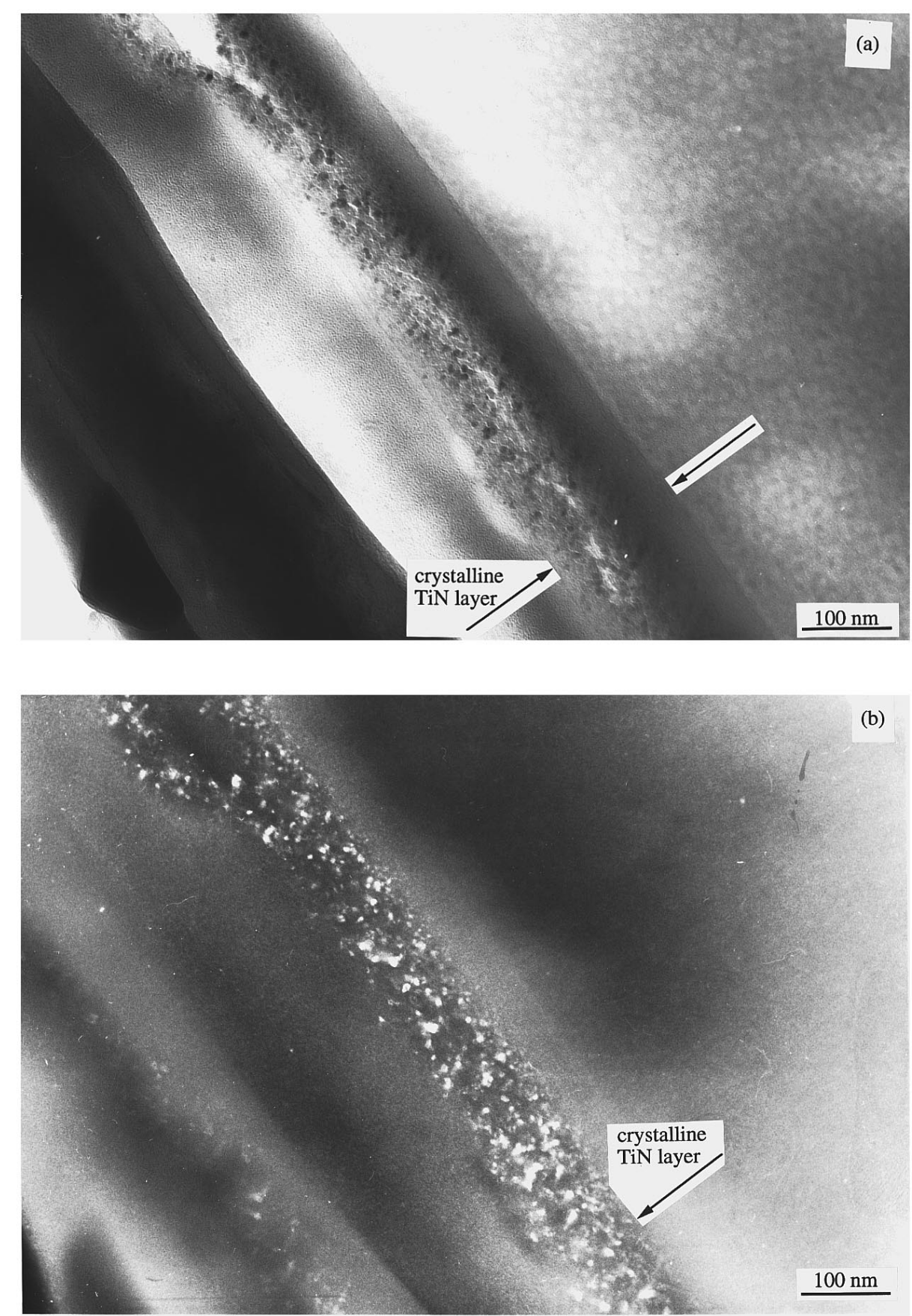

FIG. 5. (a) Bright field image, (b) dark field image and (c) selected area diffraction of the soda lime glass implanted with $\mathrm{Ti}+\mathrm{N}$ to $3 \times 10^{17} \mathrm{~cm}^{-2}$. 


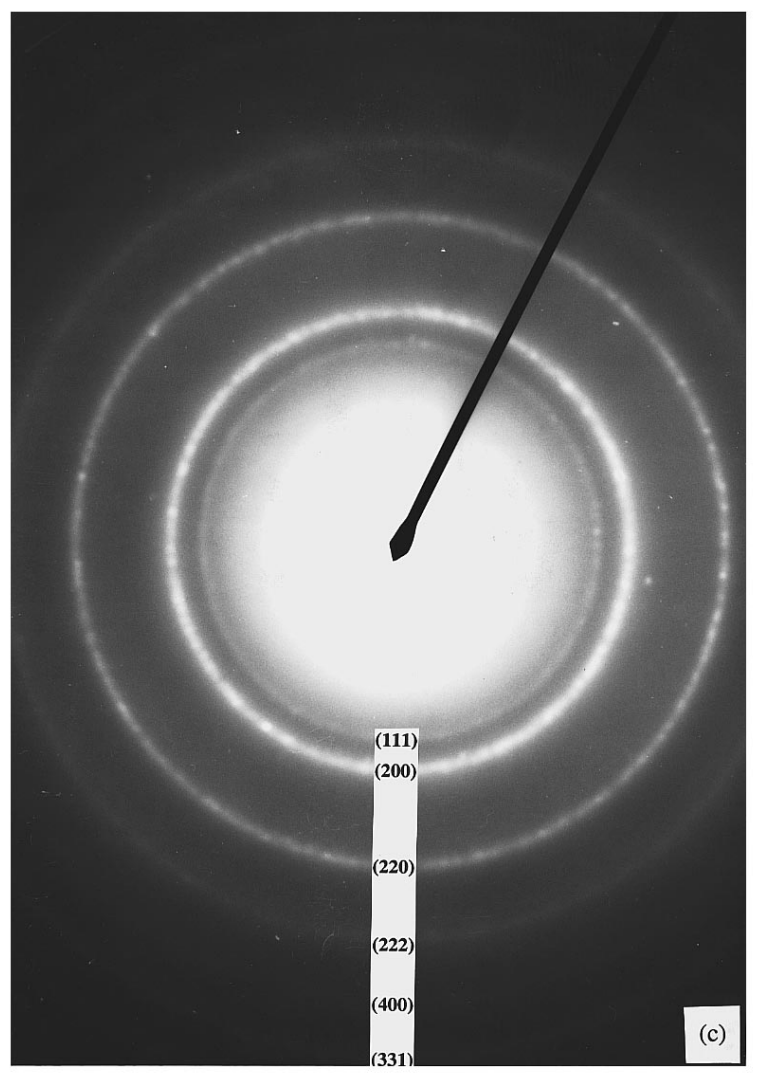

FIG. 5. (Continued.)

sharp rise in the IR reflection and percent solar rejection above $1 \times 10^{17} \mathrm{~cm}^{-2}$. Results from MULTFILM, assuming that TiN consumes either all the $\mathrm{Ti}$ or roughly $60 \%$ of the $\mathrm{Ti}$, show that the latter agrees better with measurements. This is confirmed by the plots of percent reflectance as a function of $\mathrm{Ti}$ as TiN, shown in Fig. 7. Note that for low doses, the best fit to the data is obtained assuming little or no $\mathrm{Ti}$ as $\mathrm{TiN}$, but all of it as $\mathrm{TiO}_{2}$. However, at higher doses, the best fit occurs with about $60 \%$ of $\mathrm{Ti}$ as $\mathrm{TiN}$ and the balance as $\mathrm{TiO}_{2}$. Also of practical significance is the comparatively small increase

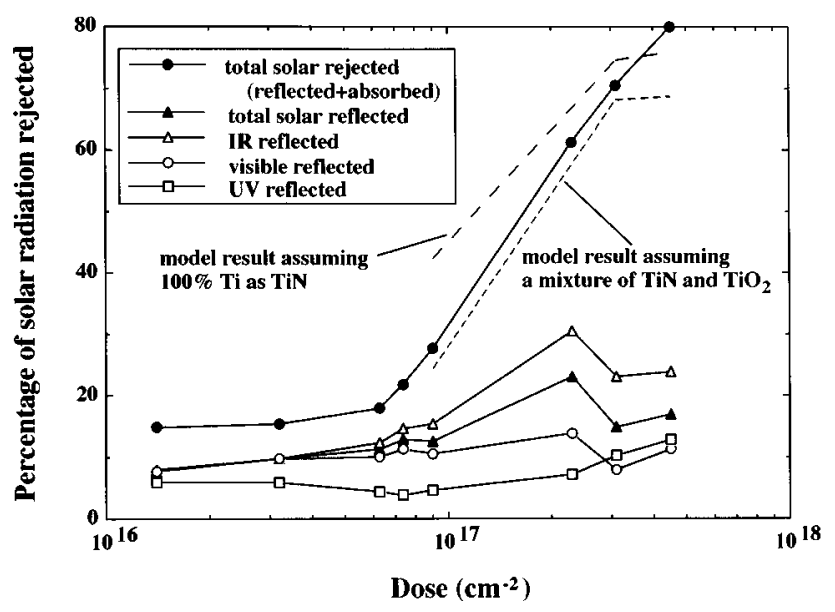

FIG. 6. Percent of incident radiation reflected vs dose for selected wavelength ranges.
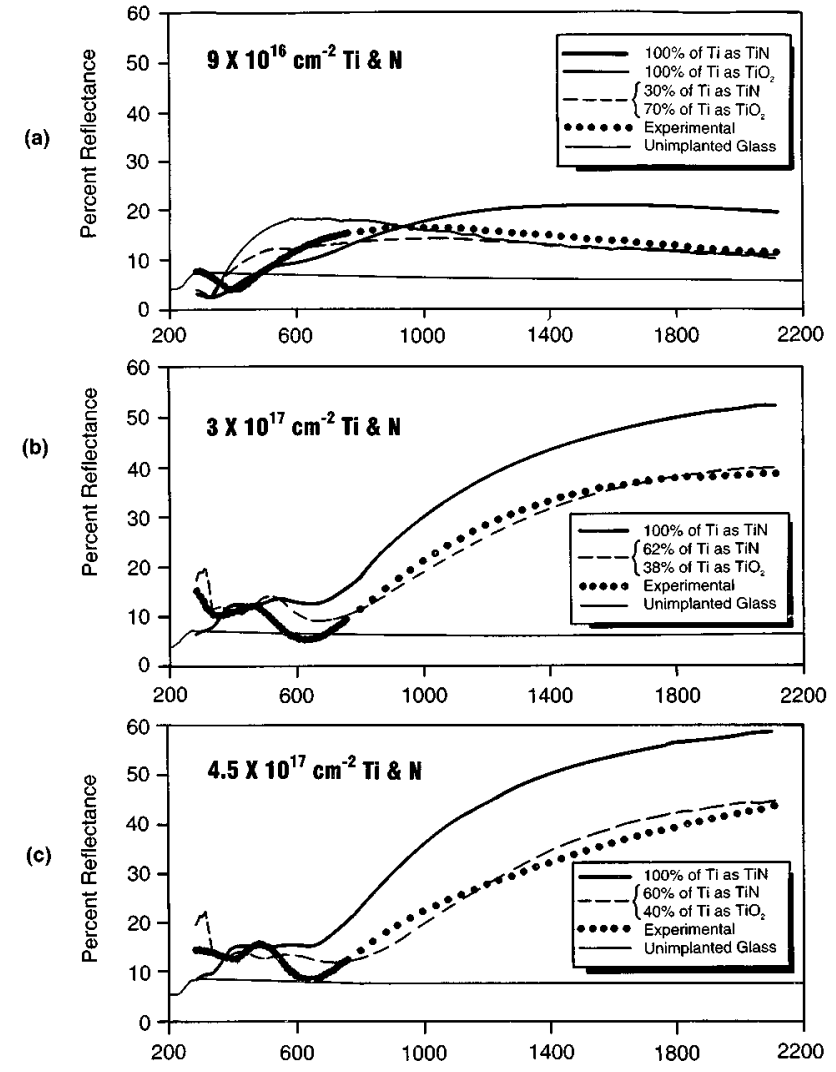

FIG. 7. Percent reflectance of soda lime glass implanted with $\mathrm{Ti}+\mathrm{N}$ to doses of (a) $9 \times 10^{16} \mathrm{~cm}^{-2}$, (b) $3 \times 10^{17} \mathrm{~cm}^{-2}$, and (c) $4.5 \times 10^{17} \mathrm{~cm}^{-2}$, as a function of the percent of $\mathrm{Ti}$ as $\mathrm{TiN}$.

in visible light reflected over the entire dose range. Calculations performed using MULTFILM for a pure, 50-nm-thick TiN layer on soda lime glass, yielded a total solar rejection of $64 \%$, inferior to the $80 \%$ rejection value at the highest implanted dose.

The abrupt increase in IR reflection and total solar load rejection at high dose were accompanied by a change in the color of the glass from a metallic silver to a distinct gold color. The gold color is indicative of the TiN phase in deposited films and is consistent with XPS, x-ray, and SAD evidence of the formation of a TiN phase. Hence, it can be concluded that co-implantation of $\mathrm{Ti}$ and $\mathrm{N}$ to doses $>9 \times 10^{16} \mathrm{~cm}^{-2}$ (33 at. $\% \mathrm{Ti}$ and $\mathrm{N}$ ) results in the formation of a buried crystalline TiN phase which exhibits optical properties similar to those of a deposited surface film.

\section{CONCLUSIONS}

Implantation of $\mathrm{Ti}$ and $\mathrm{N}$ into soda lime glass results in composition profiles where the $\mathrm{N}$ concentration closely follows that of the titanium. Anomalously deep profiles are observed at doses above $3 \times 10^{17} \mathrm{~cm}^{-2}$, due to the formation of a crystalline phase. XPS, x-ray diffraction, and selected area diffraction in TEM confirm that a crystalline TiN phase was formed at high doses $\left(>9 \times 10^{16} \mathrm{~cm}^{-2}\right)$ of $\mathrm{Ti}(\mathrm{N})$. The phase is consistent with B1-type cubic TiN and has a thickness of $140 \mathrm{~nm}$ after a dose of $3 \times 10^{17} \mathrm{~cm}^{-2} \mathrm{Ti}+\mathrm{N}$. Optical measurements show that solar load rejection increased abruptly 
above a dose of $9 \times 10^{16} \mathrm{~cm}^{-2}$. The percentage of solar energy rejected reached $80 \%$ at a dose of $4.5 \times 10^{17} \mathrm{~cm}^{-2}$ $\operatorname{Ti}(\mathrm{N})$, which corresponds to $\sim 37$ at. $\% \operatorname{Ti}(\mathrm{N})$.

\section{ACKNOWLEDGMENTS}

The authors acknowledge Larry Haack and Peter Schmitz, Scientific Research Laboratory of Ford Motor Company, for XPS analysis and interpretation, the Michigan Ion Beam Laboratory for Surface Modification and Analysis at the University of Michigan, William Boyer for his help with x-ray diffraction, and Hal Estry of the Electron Microbeam Analysis Laboratory for his help with XPS. Support for this work was provided by the Glass Division of the Ford Motor Company.

\footnotetext{
${ }^{1}$ A. K. Rai, R. S. Bhattacharya, and S. C. Kung, Mater. Lett. 13, 35 (1992). ${ }^{2}$ P. Mazzoldi, F. Caccavale, E. Cattaruzza, A. Boscolo-Boscoletto, R. Bertoncello, A. Glisenti, G. Battaglin, and C. Geradi, Nucl. Instrum. Methods B 65, 367 (1992).

${ }^{3}$ G. Battaglin, in Modification Induced by Irradiation in Glasses, edited by P. Mazzoldi (Elsevier, Amsterdam, 1992), p. 11.
}

${ }^{4}$ R. Bertoncello, A. Glisenti, G. Granozzi, G. Battaglin, E. Cattaruzza, and P. Mazzoldi, Mater. Res. Soc. Symp. Proc. 268, 325 (1992).

${ }^{5}$ E. P. EerNisse, J. Appl. Phys. 45, 167 (1974).

${ }^{6}$ A. P. Webb, L. Allen, B. R. Edgar, A. J. Houghton, P. D. Towsend, and C. W. Pitt, J. Phys. D 8, 1567 (1975).

${ }^{7}$ A. P. Webb and P. D. Towsend, J. Phys. D 9, 1343 (1976).

${ }^{8}$ C. Wang, Y. Tao, and S. Wang, J. Non-Cryst. Solids 52, 589 (1982).

${ }^{9}$ I. K. Naik, Appl. Phys. Lett. 43, 519 (1983).

${ }^{10}$ I. K. Naik, Proc. SPIE 460, 56 (1984).

${ }^{11}$ R. F. Haglund, Jr., H. C. Mogul, R. A. Weeks, and R. A. Zuhr, J. NonCryst. Solids 130, 126 (1991).

${ }^{12}$ J. F. Ziegler, J. P. Biersack, and U. Littmark, The Stopping and Range of Ions in Solids (Pergamon, New York, 1984), p. 1.

${ }^{13}$ L. R. Dolittle, Nucl. Instrum. Methods B 9, 334 (1985).

${ }^{14}$ S. N. Bunker and A. J. Armini, Nucl. Instrum. Methods B 39, 7 (1989).

${ }^{15}$ J. C. Zwinkels, M. Noel, and C. X. Dodd, Appl. Opt. 33, 7941 (1994).

${ }^{16}$ Parry Moon, J. Franklin Inst. 203, 583 (1940).

${ }^{17}$ Proprietary code, Ford Motor Company, Glass Division, 15000 Commerce Drive North, Dearborn, MI 48120.

${ }^{18}$ L. Martina, Sol. Energy Mater. 15, 21 (1987).

${ }^{19}$ H. Z. Wu, T. C. Chou, A. Mishra, D. R. Anderson, J. K. Lampert, and S. C. Gujrathi, Thin Solid Films 191, 55 (1990).

${ }^{20}$ H. J. Beattie, Jr. and F. L. Ver Snyder, Trans. ASME 45, 397 (1953). 